\title{
Economia criativa, um paradigma de política pública con- temporâneo? Uma discussão conceitual
}

Creative economics as a paradigm of contemporaneous public policy? A conceptual discussion

¿Economía creativa, un paradigma de política pública contemporáneo? Una discusión conceptual

Karina Poli Lima da Cunha

- Doutoranda em Ciências da Comunicação na Escola de Comunicações e Artes da Universidade de São Paulo (ECA-USP), com bolsa da Fapesp

- Mestre em Ciências da Comunicação pela ECA-USP

- Graduada em História pela Pontifícia Universidade Católica de São Paulo (PUC-SP)

- $\quad$ E-mail: karinapoli@uol.com.br

\section{Mitsuru Higuchi Yanaze}

- Doutor em Ciências da Comunicação pela Escola de Comunicações e Artes da Universidade de São Paulo (ECA-USP)

- Mestre em Business Administration pela Michigan State University

- Graduado em Publicidade e Propaganda pela ECA-USP

- Especialista em Administração de Empresas pela Fundação Getúlio Vargas (FGV)

- Professor titular do Departamento de Relações Públicas, Propaganda e Turismo da ECA-USP

- Coordenador do Centro de Estudos de Avaliação e Mensuração em Comunicação e Marketing (Ceacom) da ECA-USP

- Consultor de empresas e palestrante

- E-mail: mitsuruyanaze@uol.com.br 


\section{Resumo}

Esse trabalho é fruto de uma discussão teórica metodológica que Karina desenvolve em sua tese de doutorado. Parte da bibliografia citada foi trazida de visitas técnicas à Inglaterra para vivências em universidades a fim de entender como o conceito de economia criativa está incorporado aos programas, projetos e ações de políticas públicas de diferentes países influenciados pelos discursos de agencias multilaterais, tais como a Unesco e a Unctad, e por pesquisas acadêmicas internacionais.

PALAVRAS-CHAVE: ECONOMIA CRIATIVA • ECONOMIA DA CULTURA •INDÚSTRIAS CRIATIVAS • POLITICAS CULTURAIS • FINANCIAMENTO DA CULTURA.

\section{Abstract}

This paper results from a theoretical methodological discussion that Karina develops in her doctorate thesis. A part of the quoted bibliography comes from technical visits to England for experience in universities in order to obtain an understanding of how the concept of creative economics is incorporated with the programs, projects and actions of the public policies of various countries that are influenced by the discourse of multilateral agencies, such as Unesco and Unctad, as well as a result of international academic surveys.

\section{KEYWORDS: CREATIVE ECONOMICS • ECONOMICS OF CULTURE • CREATIVE INDUSTRIES • CULTURAL POLICIES • FINANCING OF CULTURE.}

\section{Resumen}

Este trabajo es el fruto de una discusión teórica metodológica que Karina desarrolla en su tesis de doctorado. Parte de la bibliografía citada fue acarreada de visitas técnicas a Inglaterra para vivencias en universidades a fin de entender cómo el concepto de economía creativa está incorporado a los programas, proyectos y acciones de políticas públicas de diferentes países influenciados por los discursos de agencias multilaterales, tales como la Unesco y la Unctad, y por investigaciones académicas internacionales.

\section{PALABRAS CLAVES:ECONOMÍACREATIVA •ECONOMÍA DE LACULTURA•INDUSTRIASCREATIVAS•POLÍTICASCULTURALES • FINANCIAMIENTO DE LA CULTURA.}


$\mathrm{E}$

ste artigo tem o objetivo de trazer uma discussão a respeito de elementos teórico-metodológicos sobre a economia criativa. Partiremos de dois modelos de analise muito utilizados em trabalhos sobre esse tema, que geram confusões comuns sobre o conceito de economia criativa. Assim, dividimos o texto em duas partes. Na primeira, contextualizamos historicamente o surgimento do conceito de indústrias criativas e a influência do paradigma inglês de políticas culturais em vários países do mundo. Na segunda parte, trabalhamos esse conceito inserido no ambiente acadêmico e descrevemos dois modelos que têm sido amplamente utilizados, tanto na elaboração de programas, projetos e ações de países que buscam programar políticas públicas culturais, como em pesquisas acadêmicas.

\section{O NOVO PARADIGMA DE POLÍTICA CULTURAL: AS INDÚSTRIAS CRIATIVAS E O CONTEXTO ANGLO-SAXÃO}

As políticas culturais inglesas entre 1980 e 1990 estavam divididas em duas prioridades para estabelecer as relações do Arts Council: a primeira, visando a uma maior preservação das belas artes e do patrimônio; e a segunda, a uma maior atenção à desregulamentação do setor da comunicação. Na década de 1980, com a onda de privatização encampada pelo governo conservador de Margareth Thatcher, o setor das comunicações cedeu às pressões das grandes empresas interessadas na ampliação da concorrência, e o modelo europeu de serviço público começou a ser desmontado pela liberalização empreendida em todo o continente. No mesmo contexto, as mudanças tecnológicas constantes passaram a exigir a adequação das televisões públicas ao cenário digital (Hesmondhalgh, 2005).

Outros países eregiões tiveram contextos diferentes, mas todos estavam lidando coma desindustrialização das grandescidades, o aguçamento da concorrência global, incluindo as indústrias culturais, em todos os casos. No caso inglês, podemos ver uma bifurcação geral entre a política das indústrias culturais que priorizava o mercado externo de grande escala em nível global, e as políticas culturais de nível local e nacional de desenvolvimento, que se tornaram cada vez mais ligadas à regeneração urbana liderada pela cultura. Embora os níveis de autonomia política e financeira das cidades difiram entre os países desenvolvidos, em geral a capacidade dos governos municipais para planejar e executar estratégias de regeneração econômicas e culturais nas décadas de 1980 e 1990 era muito limitada. Algumas cidades inglesas e seus governos estavam preparados para planejar os espaços públicos e ajudar a promover uma nova onda de desenvolvimento urbano em áreas centrais anteriormente estagnadas. E foi nesse contexto que a agenda da indústria cultural ganhou sua real força na Inglaterra. Na década de 1980 as culturas urbanas marginais de produção e consumo cultural não só se organizaram em mercados independentes, como passaram a ser reconhecidas por governos municipais e por promotores imobiliários como fontes de valor (O'Connor, 2011, p. 39-42).

Com a ideia de que a produção criativa poderia mobilizar a cultura e o conhecimento de forma mais autônoma para desenvolver a capacidade intelectual, instrumentos políticos e recursos financeiros foram empenhados na Inglaterra para se envolver na construção de um novo tipo de economia. Esse discurso está em grande parte nas coalizões e ideias políticas que foram construídas pelo Partido Trabalhista Inglês e publicadas em 1996, em um manifesto do New Labour. Ele foi apresentado como a marca do partido e foi amplamente utilizado entre 1997 e 2010. 0 governo do Reino Unido sob a bandeira do New Labour cunhou o termo indústrias criativas em 1997, tomando emprestada a "Creative nation" australiana. Em 1997 o governo criou um novo ministério: o Departamento de Cultura, Mídia e Esporte (DCMS), cujas áreas de atuação até hoje são: artes e cultura, esporte e lazer, mídia e comunicação. 0 objetivo do governo foi criar empregos e apoiar as empresas a crescer.

Diferentemente do conceito de indústria cultural que nasce no ambiente acadêmico, o conceito indústria criativa surge no ambiente político. E é da Austrália que vem o primeiro olhar mais atento da academia sobre o tema da economia criativa e 
das indústrias criativas. A Austrália pode ser considerada como uma espécie de founding father da temática das indústrias criativas, pois foi o governo australiano que, em 1994, desenvolveu o conceito de "Creative nation" com base em uma política cultural voltada para a requalificação do papel do Estado no desenvolvimento cultural do país (Miguez, 2007, p. 15).

\section{DIFERENTES ABORDAGENS TEÓRICO-METODOLÓGICAS PARA ENTENDER A INDÚSTRIAS CRIATIVAS COMO O NOVO PARADIGMA DE POLÍTICA CULTURAL}

Tratar das questões conceituais sobre a indústria criativa não é algo simples. Estas não se constituem dentro de um campo do saber isolado, alocado em uma área científica específica. Essas questões estão relacionadas a objetos de pesquisas comuns e multidisciplinares, inseridos em discussões de diferentes áreas. As indústrias criativas aparecem como um novo paradigma global de politicas públicas que colocou o binômio cultura/desenvolvimento local como pilar de sua proposição, políticas que ganharam força no final dos anos 1990 e se tornaram paradigma de desenvolvimento econômico na primeira década do século XXI.

Nascidas no cerne da configuração da sociedade do conhecimento e do neoliberalismo, as indústrias criativas vêm a ser o exemplo de política pública da contemporaneidade que incorpora novos conceitos para questões de diversas áreas e campos do saber. Ao tomarmos como base para esse argumento um estudo publicado em 2014 na revista Journal of Economics, Business and Management sobre a estrutura intelectual dos estudos da indústria criativa, escrito por Chin-Yu Chen e Jwu-Jenq Chen, que analisaram 20.345 citações de trabalhos sobre a economia criativa de 999 artigos publicados em revistas científicas disponíveis na web entre 2003-2012, podemos perceber que, atualmente, as indústrias criativas são objetos de pesquisa em várias áreas do saber.

A analise das citações e cocitações foram conduzidas para identificar as mais importantes publicações acadêmicas e temas que fazem parte das pesquisas sobre indústrias criativas no mundo. A pesquisa teve o objetivo de ajudar a identificar a direção dos estudos sobre as indústrias criativas. E foi constatado que os países de origem dos principais textos e autores são, nesta ordem: Estados Unidos, Inglaterra, Austrália, Canadá, Alemanha, Suécia, Holanda, França, Japão, China, Dinamarca, Nova Zelândia, Itália, Espanha, Bélgica. E as áreas das principais revistas onde esses trabalhos foram publicados são, nesta ordem: negócios e economia, geografia, ciências do meio ambiente, engenharia, administração pública, comunicação, urbanismo, estudos culturais, sociologia (CHEN, C.; CHEN, J. 2014).

As definições das indústrias criativas estão de acordo com o desenho das estruturas das indústrias culturais, da regulamentação das legislações de propriedade intelectual e das políticas públicas de cada local. As condições nacionais são diferentes, com diferentes problemas, e por isso as indústrias criativas têm estruturas e nomes diferentes em cada países. Por exemplo: na Inglaterra, Austrália e Islândia, o nome é indústrias criativas; nos Estados Unidos, direitos autorais e de copyright das comunicações e do entretenimento; para a Unesco, a União Europeia e a Organização para a Cooperação e Desenvolvimento Econômico (OCDE), Industrias culturais e criativas; na Suécia e Dinamarca, economia da experiência.

A rigor, foi depois de 2000 a publicação da primeira obra sobre o assunto das indústrias criativas. Trata-se do livro The creative economy: how people make money from ideas, publicado em Londres por John Howkins. Dois outros livros publicados nos Estados Unidos, o do professor de Economia da Universidade de Harvard, Richard Caves, intitulado Creative industries, e 
0 de Richard Florida, The rise of the creative class, em 2002, marcam a produção bibliográfica das indústrias criativas. No entanto, esses trabalhos não chegaram a tratar de questões de ordem conceitual no sentido de uma delimitação mais rigorosa do que venha a ser a economia criativa e as indústrias criativas. Segundo Miguez (2007), Richard Caves vai tratar das relações que se estabelecem entre os diversos campos do fazer artístico - que ele denomina de creative activities, e o campo da economia. Enquanto Florida está preocupado em refletir sobre o que denomina de creative class, ou seja, profissionais tais como cientistas, artistas, poetas, arquitetos, editores, formadores de opinião, que compartilham o fato de estarem vinculados a algum creative process.

Ainda sobre o olhar da academia para a economia e as indústrias criativas, Miguez destaca o simpósio internacional organizado em dezembro de 2002 em Brisbane, na Austrália, que reuniu pesquisadores e estudiosos da recém-criada Creative Industries Faculty da London School of Economics, do Massachusetts Institute of Technology e da New York University, com o intuito de refletir sobre o significado e os impactos sociais e culturais da economia criativa e de contribuir para a construção de uma agenda dedicada a essa temática. 0 resultado desse encontro, intitulado New Economy, Creativity and Consumption Symposium, foi posteriormente reunido numa edição especial do International Journal of Cultural Studies, que veio a público em março de 2004. Apenas em 2005 é publicado um livro que diz respeito às questões de ordem teórico-conceitual. Trata-se do trabalho organizado por John Hartley sob o título Creative industries, publicado em Oxford, na Inglaterra, e que, em conjunto com importantes pesquisadores, aborda variados e relevantes aspectos, permitindo, pela primeira vez, uma compreensão mais substantiva da temática da economia criativa e das indústrias criativas (Miguez, 2007).

Contudo, a expressividade no trato da temática da economia criativa e das indústrias criativas está nos documentos de políticas, planos estratégicos, programas de ação e projetos de órgãos e agências governamentais, especialmente em países anglófonos. Apesar da grande aceitação internacional do conceito e da sua crescente importância no mundo contemporâneo, a indústria criativa ainda provoca bastante polêmica. Existe uma série de discussões em torno do tema. Um primeiro ponto de reflexão são as duas visões sobre as indústrias criativas: de um lado, aquela que privilegia o núcleo criativo e a produção da arte e da cultura; e, de outro, aquela que privilegia os nexos industriais e a relação com a cadeia como um todo em grandes proporções. No ambiente acadêmico, alguns modelos se apresentam como instrumentos de analises das indústrias criativas. Para este artigo trabalharemos com dois: o modelo dos círculos concêntricos, que oferece um método de mensuração econômica da estrutura das indústrias culturais e criativas; e o método dos textos simbólicos, próprio da área de comunicação, que procura analisar os discursos ideológicos por trás das ações políticas públicas e observa a indústria criativa como um resultado de ação pública que privilegia a lógica das industrias culturais e a assimetria econômica do mercado global.

O uso do termo indústria criativa foi de uma valiosa importância estratégica para as políticas de cultura, que tiveram consequências para empresas pequenas e médias, indústrias e governos. Por um lado, permitiu que os principais produtores de software os conglomerados culturais da indústria estabelecessem alianças legitimadas pelo Estado, com as empresas menores e com os trabalhadores culturais, com base no esforço da defesa da propriedade intelectual. Para alguns pensadores, os estudiosos que preferem usar o termo indústrias culturais são mais cautelosos ao analisar os resultados de tais políticas culturais, entendendo as estratégias como uma mudança nos critérios de financiamento, que justificam os cortes aos subsídios às artes. Na década de 2000, as ideias sobre as indústrias criativas percorreram o mundo e planos foram desenvolvidos, tanto em nível nacional e local, quanto no nível regional. Houve uma implacável produção de documentos mapeamentos estratégicos e o "modelo" britânico de indústrias criativas foi adotado como orientação política por vários países e agências multilaterais. A "indústria criativa" vem sendo considerada como um dos segmentos econômicos com maiores possibilidade de crescimento no mundo contemporâneo. Mas a questão que se coloca é: para quem estão destinados os benefícios dessa política, se são muitos os interesses envolvidos? Essa indagação deixa claro um profundo conjunto de 
questões que se referem à forma com que a cultura opera nas economias modernas e, de certa forma, envolve a posição da própria cultura em relação à sociedade (Hesmondhalgh, 2007).

A mais óbvia das tensões provocadas pelas diferentes abordagens das indústrias criativas refere-se ao financiamento. A inclusão dos setores criativos na pasta da cultura faz parte da construção de uma justificativa para as estratégias de valorização da dimensão cultural do desenvolvimento, e de atração de recursos orçamentários para a pasta da cultura, tendo em vista os grandes cortes para a proteção das belas artes. A tensão se revelaria numa eventual concorrência interna pelos recursos da cultura entre as áreas tradicionais das belas artes, do patrimônio histórico, do folclore, com os novos setores criativos e os projetos de recuperação urbana. E permitiu que as indústrias culturais usassem argumentos para obter apoio público para a formação dos trabalhadores criativos, que originalmente beneficiariam as indústrias das tecnologias da informação e da comunicação. Este argumento também teve implicações mais amplas à medida que a política de educação das universidades se apropriou do conceito no sentido de fortalecer o discurso das habilidades e incentivar a formação de trabalhadores inovadores e criativos (Hesmondhalgh, 2007; Oliveira; Starling, 2012).

\section{O modelo dos círculos concêntricos}

David Throsby é professor do Departamento de Economia da Universidade de Macquarie, na Austrália. Conhecido internacionalmente por seu trabalho como economista com interesses específicos na economia das artes e da cultura, é um dos intelectuais que mais influenciaram os modelos para mensuração da economia criativa e da cultura. Suas publicações recentes relacionadas com a economia criativa incluem Handbook of the economics of art and culture e Beyond price: value in culture, economics, and the arts. Outro livro de David Throsby é Economics of cultural politics, publicado pela Cambridge University Press em 2010. Throsby tem sido um consultor influente em uma série de organizações internacionais, como a Unesco, a Unctad, a OCDE, a União Europeia e o Banco Mundial. Uma das suas principais contribuições para a edificação na nova abordagem científica da economia criativa foi a criação do modelo de análise dos "círculos concêntricos", que é uma referência em diversos trabalhos e documentos internacionais sobre as industrias criativas. 0 modelo foi apresentado tendo como base os elementos inseridos nos "bens culturais" que fazem com que as "indústrias criativas" estabeleçam valor (Throsby, 2010).

O modelo de círculos concêntricos vem sendo adorado em diferentes proposições de política cultural e identifica elementos fundamentais para serem considerados em suas analises como instrumento de gestão e administração pública. Entre os elementos descartados por Throsby que devem ser considerados em uma proposição de política cultural estão: a relação arte-cultura-patrimônio no sentido de atribuir valor e definir os compromissos financeiros e as despesas públicas; identificar o potencial e o papel das indústrias culturais na contribuição para a renda, para o crescimento econômico e para a criação de empregos; avaliar esses elementos em nível nacional, regional ou local; desenhar políticas mais específicas que afetam o mercado de trabalho para cultura e mapear o comércio internacional de bens e serviços culturais; reconhecer e identificar o envolvimento da educação em matéria de política cultural, na qual a exposição e a participação ativa da população na experiência com a música, as artes visuais, a dança não só venham enriquecer a vida cultural, mas também melhorar as habilidades de sua aprendizagem em outras áreas.

Esse modelo traz uma abordagem metodológica que reconhece: o novo papel das cidades e o protagonismo da cultura para contribuir com a revitalização de áreas urbanas degradadas, melhorando a habitabilidade e estimulando o crescimento econômico urbano e regional; a potencialidade da inovação das indústrias criativas para estabelecer novas relações com o meio ambiente e com práticas ambientais, por meio da contribuição de ideias criativas em designe arquitetura que tragam soluções de melhora para o meio ambiente e a qualidade de vida; aproximar e fortalecer a política na área das comunicações com as 
políticas culturais, não somente por meio do impulso pela relevância econômica, como também pela importância dos meios de comunicação, principalmente os digitais no que se refere à individuação dos meios e à pulverização de conteúdos criativos. Para Throsby, uma análise econômica da política cultural deve começar em relação à natureza dos produtos e serviços. Se, por um lado, os bens e serviços são commodities comuns como quaisquer outros produtos que circulam na economia, a aplicação da política econômica para a sua produção, distribuição, marketing, transporte e consumo não seria diferente. Mas, por outro, os bens e serviços culturais têm qualidades distintas a commodities comuns. 0 autor propõe uma definição para resolver essa dificuldade e fornece uma abordagem que difere os bens e serviços culturais e criativos (Throsby, 2010).

Os círculos concêntricos de Throsby compreendem o nível da profundidade do setor criativo, entendendo-se que esse setor é composto por círculos sobrepostos que, quanto mais próximos do núcleo, mais autêntica tornam a experiência artística e o bem cultural. No núcleo do círculo está o campo criativo, que está relacionado ao trabalho do artista, seja a composição da obra, a letra, os geradores de direitos autorais, enfim. Consideramos que as funções de transformação da ideia criativa em produto cultural, e a gestão dos processos para conduzi-lo até o consumidor, estão representados dentro das estruturas e no círculo seguinte, que é o das indústrias culturais. Quando utilizamos o modelo dos círculos concêntricos de Throsby, sabemos que estamos buscando compreender os impactos econômicos das atividades culturais. Esse modelo proporciona aos administradores das políticas culturais uma base para formulação de classificações e estatísticas para compreender 0 valor acrescentado à ideia criativa e outros índices relevantes para efeitos de política cultural (Throsby, 2010).

Se olharmos para os impactos econômicos das atividades culturais, fica mais claro compreender a proposição dos círculos concêntricos, uma vez que, por pertencer ao universo do simbólico, a criação é a essência da criatividade, e esta, por sua vez, gera valor por meio do direito autoral. Já ao olharmos para o círculo seguinte, entendemos mais facilmente o papel das indústrias culturais na transformação dos bens simbólicos em produtos, principalmente se observarmos pelo ponto de vista das grandes escalas. 0 círculo das atividades e indústrias criativas já está envolvido aos processos que, agrupados, representam o novo olhar das políticas públicas que pensam a transversalidade da cultura em outras atividades que utilizam o conteúdo criativo, e o seu impacto na economia como um todo. 0 entendimento das indústrias culturais e criativas pelo ponto de vista das políticas públicas justifica a legitimação do conceito na criação de métodos de mensuração da Economia da Cultura.

\section{0 modelo de textos simbólicos}

Esse modelo é típico da abordagem para as indústrias culturais, tendo sido originado na tradição da economia política da comunicação e da cultura e na influência dos estudos culturais devido à aproximação do conceito da diversidade cultural e do multiculturalismo como proposição da nova política pública para a cultura, especialmente no Reino Unido. 0 modelo analisa os processos pelos quais a cultura de uma sociedade é formada e reproduzida por meio da interpretação da produção cultural, de sua disseminação e do consumo das mensagens ou textos simbólicos que são transmitidos mediante os veículos de comunicação, como filme, radiodifusão e imprensa. Essa linha de pensamento, principalmente na Inglaterra, estuda as políticas culturais dentro do campo multidisciplinar no qual se inserem as pesquisas realizadas nos centros universitários que observam a mídia e as relações com a cultura.

Os pensadores da escola teórica da Economia Política da Comunicação e Cultura Centre (EPCC) criticam o uso do termo indústria criativa e procuram deixar claro dentro do ambiente acadêmico que este é um conceito criado como ferramenta de um novo discurso político ideológico usado em documentos oficiais de instâncias institucionais multilaterais e governos para legitimar a cultura como um dos recursos principais de um novo paradigma de desenvolvimento econômico. 
0 modelo dos textos simbólicos observa o conceito de indústrias criativa como um modelo de mensuração dos impactos econômicos das indústrias culturais, que está baseado na reunião das atividades relacionadas com a produção industrial da cultura, bem como outras atividades que têm como insumo a criatividade, para apresentar e legitimar um discurso e um modelo de política cultural capaz de gerar índices de desenvolvimento que mascaram os impactos negativos do neoliberalismo e que, de certa maneira, abriram uma terceira via para a ideologia de esquerda, principalmente para o Partido Trabalhista no cenário inglês do final da década de 1990.

David Hesmondhalgh é professor de Mídia, Música e Cultura e diretor do Media Industries Research Centre na School of Media and Communication da Universidade de Leeds, na Inglaterra. Para ele a indústria criativa é um termo originário no ambiente político para legitimar um discurso da cultura pela perspectiva do desenvolvimento e da regeneração urbana. Em seu texto Cultural and creative industries (2007), os impactos sobre a mercantilização da cultura e a incorporação das indústrias na noção das políticas públicas foram estudados por meio de documentos da Unesco que produziram um substancial volume de pesquisa sobre as indústrias culturais em 1982. Nesses estudos foram apresentadas as desigualdades internacionais em termos de volume de recursos da industrias culturais, agravadas pelo investimento de grandes empresas ocidentais transnacionais. Esses estudos também legitimaram a criação de parâmetros e modelos de uma política cultural internacional que foi utilizada como paradigma nas diferentes conferências das várias instâncias de governança transnacional multilateral.

A inserção das indústrias culturais como objeto das políticas culturais aconteceu em diferentes países. Porém, o contexto político da Grã-Bretanha apresentou-se mais radical propondo uma política cultural mais democrática na difusão da cultura popular por meio das industrias culturais e em detrimento do financiamento das belas artes. Uma das primeiras propostas veio do Conselho da Grande Londres (GLC) em 1983, criado sob a gestão do Partido Trabalhista inglês e abolido durante a gestão do governo conservador em 1986. Esse conselho se posicionou contra as noções elitistas e idealistas de arte e trabalhou com outros critérios para a definição dos financiamentos. Para o conselho, a política cultural devia levar em conta as práticas culturais e o gosto da maioria das pessoas. Ele criou um plano com formas comerciais de fomento à cultura, principalmente por meio do serviço público de radiodifusão. 0 objetivo não era celebrar a produção comercial, mas reconhecer sua centralidade na cultura moderna, uma posição-chave que mudou o foco estratégico da política cultural, agora não mais centrada no artista, mas sim no público. A política de subsídio aos criadores deveria dar lugar ao foco na distribuição e à exibição para o alcance de audiência. Houve um segundo elemento das políticas do GLC que criou as bases para a nova proposição de política cultural: o investimento público no setor como um meio para regeneração econômica. As políticas também foram direcionadas para a dinamização do turismo no sentido de tornar áreas urbanas atraentes para essa atividade. Em muitas cidades inglesas as políticas culturais tornaram-se ligadas às estratégias para usar a cultura para fins urbanos de regeneração, e a ascensão dessas políticas culturais se deu inicialmente sob a forma de "quarteirões culturais das cidades pós-industriais". As políticas para as indústrias culturais vieram para satisfazer o desejo de rápido crescimento do papel da cultura em outras instâncias das políticas públicas, incluindo os meios de comunicação, considerando as taxas de retorno sobre o investimento público, e 0 aumento constante e global da aceitação do neoliberalismo (Hesmondhalgh, 2007, p. 555-557).

Na virada do século, a cultura foi completamente incorporada à noção geral de criatividade, e a noção de clusters criativos foi ainda mais significativa para fortalecer as políticas em nível municipal. Esse conceito é derivado do conceito de cluster de negócios criado pelo economista americano Michael Porter. Ele propunha um modelo de negócio pelo qual nações e regiões poderiam ganhar vantagens competitivas importantes sobre outras, se agrupassem empresas do mesmo setor em uma mesma localidade. Na década de 1990, os formuladores de política, preocupados com o desenvolvimento das indústrias de cultura, associaram-se ao crescente culto da criatividade para se beneficiar das inovações em gestão e negócios. As ideias 
sobre os clusters criativos vieram associadas ao discurso da utilização dos recursos da cultura e das artes a serviço dos projetos de regeneração urbana. Diversos festivais, museus e complexos de cinema foram incorporados pelo processo de regeneração urbana e pelo crescimento liderado pela cultura durante década de 1990. Por um lado, o conceito de indústria criativa procura promover a cultura, a diversidade e a democracia e, por outro, reconhece o lugar da comercialização, dos interesses do turismo e do emprego, estimulando uma abordagem mais empresarial das artes e da cultura, incentivando a inovação e a criatividade e dando um novo uso para edifícios antigos e locais abandonados (Hesmondhalgh, 2007, p 565-568).

\section{CONSIDERAÇÕES FINAIS}

Entendemos que o modelo dos círculos concêntricos e o modelo dos textos simbólicos são fundamentais para compreender a relação entre os diferentes conceitos que fazem parte do universo da economia criativa. 0 primeiro é um método que propõe um modelo de mensuração dos impactos das atividades ligadas às indústrias culturais e criativas nas economias, e oferece instrumentos de uso prático para agentes da administração pública e pesquisadores. Esse método é trabalhado por estudos ligados à economia da cultura, que entende as indústrias culturais como aquelas clássicas, amplamente estudadas por teóricos da economia política da comunicação e da cultura. No entanto, também compreende 0 impacto de diferentes agrupamentos de profissionais criativos que foram incorporados a uma nova lógica econômica contemporânea, que determina uma necessidade empreendedora por parte dos agentes que transitam entre os setores artísticos, das indústrias culturais e de outros setores que utilizam conteúdo cultural como insumo e também em diferentes áreas da economia que, de alguma maneira, trabalham com os artistas ou bem culturais e criativos em seus processos de comunicação com seu público alvo. Esse primeiro modelo é utilizado como referência em várias agências multilaterais, como, por exemplo, a Unesco e a Unctad.

O segundo modelo, dos textos simbólicos, é utilizado principalmente por acadêmicos da área de comunicação que, junto com outros modelos teóricos metodológicos, analisam os discursos políticos e ideológicos das esferas da comunicação e da cultura. Esse modelo entende a economia criativa e as indústrias criativas como conceitos incorporados em programas, projetos, ações de diferentes órgãos públicos contemporâneos, que defendem uma nova forma de financiamento das atividades culturais, valorizando os elementos da cultura que são transversais a outras áreas da administração pública, como economia, turismo, educação, assistência social, dando uma maior atenção para a audiência e o consumo cultural, em detrimento das velhas práticas de subsídio às belas artes. Os autores que utilizam esse modelo observam a economia criativa de uma maneira crítica em dois aspectos principais: o primeiro é aquele elemento em que o discurso coloca as indústrias criativas como um paradigma de desenvolvimento econômico sem considerar a assimetria existente entre países de centro e periferia. 0 segundo está inserido no mesmo discurso que evidencia somente elementos positivos do trabalho criativo, tais como os níveis de satisfação e autonomia, próprios dessa nova lógica de trabalho criativo, sem destacar a falta de direitos sociais e de informalidade. Retiramos esses elementos da tese para mostrar neste artigo algumas diferenças conceituais sobre os conceitos de indústrias culturais, que são objetos de pesquisa de importantes estudos da comunicação, e de economia da cultura, que é uma área acadêmica surgida na década de 1960 para atender a necessidade de pesquisas sobre 0 impacto do financiamento das artes e da sustentabilidade econômica das fundações de belas artes. Na década de 1980, gestores de políticas públicas e os pesquisadores passaram a estudar os impactos das indústrias culturais e das comunicações nas economias nacionais para entender a força política dos grandes conglomerados e a sua influência nas transformações e conduções do financiamento da cultura e o conceito de economia criativa. Assim, procuramos trazer para o texto um esclarecimento em relação ao conceito de economia criativa, entendida aqui como um novo paradigma político-ideológico de gestão pública, que influenciou os estudos da economia da cultura, a qual, no século XXI, reconhece os elementos pragmáticos desse paradigma como elementos que potencializam o desenvolvimento local. 


\section{REFERÊNCIAS}

CAVES, Richard E. Creative industries: contracts between art and commerce. Cambridge: Harvard University Press, 2000.

CHEN, Chin-Yu; CHEN, Jwu-Jenq. The intellectual structure of creative industries studies. In: 2003-2012: Invisible Taiwan. Journal of Economics, Business and Management, v. 2, n. 1, February 2014.

FLORIDA, Richard. The rise of the creative class. New York: Basic Books, 2002.

HESMONDHALGH David. Media and cultural policy as public policy. International Journal of Cultural Policy, v. 11, n. 1, 2005. . Cultural and creative industries. The Sage Handbook of Cultural Analysis, Paper a4, Job n. 5038, p. 552 552-569, 2007.

HOWKINS, John. The creative economy. how people make money from ideas. Londres: Penguin, 2001.

MIGUEZ, Paulo. Algumas notas sobre a economia da cultura. In: COSTA, Frederico Lustoso. Política e gestão cultural: perspectiva Brasil e França. Salvador: Edufba, 2013.

O'CONNOR, Justin. The cultural and creative industries: a critical history. Ekonomiaz, n. 78, 3. cuatrimestre, 2011.

OLIVEIRA, Marta; STARLING, Mônica. A economia criativa como política de desenvolvimento: cultura, criatividade e inovação. In: Economia criativa, um conceito em discussão. Belo Horizonte: Fundação João Pinheiro, 2012. p. 69-115.

THROSBY, David. Economics of cultural politics. Cambridge: University Press: 2010.

Valor na cultura e na economia das artes. Cambridge: Cambridge University Press, 2008.

THROSBY David; GINSBURGH, Victor. Economia da arte e cultura. Vol. 2. Cambridge: Cambridge University Press, 2008.

Artigo recebido em 31.7.2015 e aprovado em 19.11.2015 